\title{
Antimicrobial Activity of Phyllanthus Emblica and Allium Sativum: Comparative Analysis of Antimicrobial Action of Crude and Ethanolic Extract of These Natural Plant Products
}

\author{
${ }^{1}$ Ummey Nahor and ${ }^{2}$ Zakaria Ahmed \\ ${ }^{1,2}$ Department of Microbiology, Primeasia University, Dhaka-1213, Bangladesh
}

\begin{abstract}
The antimicrobial effects of extracts of A. sativum and P. emblica, against pathogenic Staphylococcus aureus, Escherichia coli, Pseudomonas sp., Klebsiella sp, Salmonella typhi, Salmonella paratyphi, Salmonella sp., Bacillus subtilis, Bacillus cereus were investigated using the agar well and disc diffusion method. Aqueous extracts of A. sativum and P. emblica were more effective than ethanolic extarct producing larger zones of growth inhibition. All of natural products showed the MIC values ranged from 6.25 $25.0 \mu \mathrm{g} / \mathrm{ml}$ while the $M B C$ values ranged from $12.5-100.0 \mu \mathrm{g} / \mathrm{ml}$. This study is an indication that the A. sativum and P. emblica has the potentiality to use as a source for new broad spectrum oral antibiotics.
\end{abstract}

Key words: Antimicrobial activity, crude and ethanolic extract, $M I C, M B C$.

\section{Introduction}

Plants have been the basis of many traditional medicine systems throughout the world for thousands of years and continue to provide humankind with new remedies (Samuelsson, 2004). Many drugs used in contemporary medicine have been derived from plants and were originally discovered through the traditional use by indigenous people. The use of plants as medicines Isolation and characterization of pharmacologically active compounds from medicinal plants continue today. There has been resurgence in the consumption and demand for medicinal plants. These plants are finding use as pharmaceuticals, neutraceuticals, cosmetics and food supplements. Even as traditional source of medicines and they continue to play pivotal rule. The World Health Organization (WHO) estimated that $80 \%$ of the population of developing countries still relies on traditional medicines, mostly plant drugs, for their primary health care needs. Also, modern pharmacopoeia contains at least $25 \%$ drugs derived from plants. Many other are synthetic analogues built on prototype compounds isolated from plants. Demand for medicinal plant is increasing in both developing due to growing recognition of natural products, being non-toxic, having no side-effects, easily and developed countries available at affordable prices.

Allium sativum has been in used since ancient times in India and China for a valuable effect on the heart and circulation, cardiovascular disease (Kris-Etherton, 2002; Yeh. and Liu, 2001; Gardner et al., 2003) and regular use of A. sativum may help to prevent cancer,to treat malaria, and to raise immunity. A. sativum has also proposed to treat asthma, candidiasis, colds, diabetes, and antibacterial effect against food borne pathogens like Salmonella, Shigella and Staphylococcus aureus (Teferi and Hahn 2002).Therapeutic use of A. sativum has been recognized as a potential medicinal value for thousands of years to different micro-organisms. For example, antifungal, antiviral, antibacterial antihelmantic, antiseptic and anti-inflammatory properties of A. sativum are well documented. Moreover, A. sativum extracts exhibited activity against both gram negative (E. coli, Salmonella spp. and Citrobacter sp., Enterobacter sp., Pseudomonas sp. and Kilabsella sp.) and gram positive (S. aureus, S. pneumonia, Group A Streptococcus and Bacillus anthrax) all of which are causes of morbidity world wide. Phyllanthus emblica has been used for the treatment of several disorders such as the Scurvy, Cancer and Heart diseases. The important constituent of plant leaves have the anti-neutrophilic activity and anti-platelet properties in vitro. The extracts also posses several pharmacological properties like anti-viral(HIV, AIDS, HERPES VIRUS, CMV) antimutagenic, anti-allergic, anti-bacterial activities. The present study was designed to determine the antimicrobial activity of A. sativum and P. emblica and aslo focused on the comparison of only those commercial antibiotics.

\section{Materials And Methods}

Collection of the plants: The selected parts these plants were collected from Bishoroad and.Mohakhali, Dhaka; Monohardi, Narsingdi and gaibandha sodar, Gaibandha during the months of November to December, 2011.

Test microorganisms: Bacillus subtilis, Bacillus cereus, Staphylococcus aureus, Bacillus subtilis, Bacillus cereus, Staphylococcus aureus these organisms were collected from the Microbiology research laboraroty, 
Department of Microbiology, Primeasia University of Dhaka. The pure of which was previously collected from the Microbiology Department of Dhaka University.

Pure Culture preparation: With the help of a inoculating lop, the test organisms were transferred from the pure culture to the agar slants in a laminar unit, the incubated satins were then incubated at $37^{\circ} \mathrm{C}$ for $18-24$ hours to ensure the growth of test organisms. This culture was used for sensitivity test.

Drying and Pulverization: The fresh plant products were first washed with water to remove adhering dirt and then cut into small pieces, sun dried for 4 days. After complete drying, the entire portions were pulverized into a coarse powder with the help of a blender machine and were stored in an airtight container for further use.

\section{Preparation of extracts:}

Mechanical process Aqueous extract of A. sativum and P. emblica were prepared according to methods previously reported by Onyeagba et al. (2004). $100 \mathrm{~g}$ of fresh, washed A. sativum cloves was macerated in a sterile, ceramic mortar.The homogenate was then filtered off with a sterile, muslin cloth and used directly for the sensitivity test.To ensure aseptic conditions, sterile gloves and face masks were worn and the entire extraction was carried out in a media room of the Microbiology Laboratory, Primeasia University, Dhaka.

Ethanolic process The powdered $10 \mathrm{gm}$ powders were added with $100 \mathrm{ml}$ distiled ethanol in a conical flasks.then the solution was kept in room temperature for 24-72 hours.after that the homogenate was vaccume filtered with a sterial filter paper.then the extraction was kept in a sterial container and stored at -20 degree celcicus.

Standardization of inoculums: (Murray et al. 2007) A standard stock of the bacteria isolates were prepared by suspending a loop full of each microbial growth in about $10 \mathrm{ml}$ of sterial saline . After incubation at $37^{\circ} \mathrm{C}$ for 12 $\mathrm{h}$, the turbidity was adjusted to be visually comparable with a 0.5 McFarland's standard giving a bacterial load of about $1.4 \times 10^{7}$ cfu $\mathrm{m} / \mathrm{L}$.

Susceptibility test: Suspensions of the bacterial isolates were made in sterile normal saline and adjusted to the 0.5 McFarland's standard. Each Nutrient agar (NA) agar plate was uniformly seeded by means of sterile spreader dipped in the suspension and spreaded on the agar plate surface, and the plates left on the bench for excess fluid to be absorbed (Murray et al. 2007). Wells of $5 \mathrm{~mm}$ in diameter, $4 \mathrm{~mm}$ deep and about $2 \mathrm{~cm}$ apart were punched in the NA agar with a sterile cork-borer. Approximately $100 \mu \mathrm{l}$ of the extracts were dropped into each well which filled them respectively to fullness. The setup were allowed to stabilize for $3 \mathrm{~h}$ before being incubated at $37^{\circ} \mathrm{C}$ for $24 \mathrm{~h}$ as described previously by Shahidi (2004), Murray et al. (2007) and Aibinu et al. (2007).

Determination of the minimum inhibitory concentration (MIC) and MBC The MIC of the crude extract was determined using the doubling dilution method of Sahm and Washington (1990). Briefly, $1 \mathrm{ml}$ of the reconstituted crude extract at a concentration of $100 \mathrm{mg} / \mathrm{ml}$ was added to $1 \mathrm{ml}$ of nutrient broth. $1 \mathrm{ml}$ of this extract concentration was transferred to another test tube and this dilution continued until an 7th test tube was reached, giving extract concentrations of $100,50,25,12.5,6.25,3.17$ and $1.58 . \mathrm{mg} / \mathrm{ml}$ in different test tubes(v/v in case of aqueous extract) and (w/v in case of ethanolic extract). Then $100 \mu \mathrm{l}$ of an $18 \mathrm{~h}$ culture of bacteria was inoculated into each of the test tubes and the contents horoughly mixed. The tubes were incubated at $37 \mathrm{oC}$ for $24 \mathrm{~h}$. The 8th test tube contained $1 \mathrm{ml}$ of pure solvent but no extract and served as a negative control. The test tube with the lowest concentration of the extract that did not show any detectable growth was taken as the MIC. Dilutions showing no visible growth for the MIC was sub-cultured and incubated at $37^{\circ} \mathrm{C}$ for $24 \mathrm{~h}$. The lowest concentration of the extracts yielding no growth on the NA plate was recorded as the MBC.

Test Antibiotic In our present study, the antibacterial activity of aqueous extracts and ethanol extract were investigated in compare with standard Tetracycline (30 $\mu \mathrm{g} / \mathrm{disc})$, Cipproflaxacin $(5 \mu \mathrm{g} / \mathrm{disc})$, Vancomycin

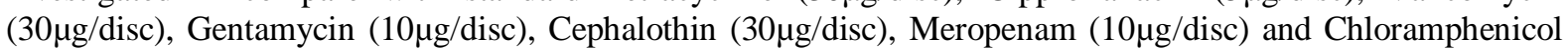
$(30 \mu \mathrm{g} / \mathrm{disc})$ antiibiotic agent a number of pathogenic Gram-positive and Gram-negative bacteria

\section{Results}

Aqueous and ethanolic extract of A. sativum, P. emblica, were tested (well method) for their antimicrobial activety against all of the selected microorganisms. In this antibacterial screening of crude extract were used at a concentration of $100 \mu \mathrm{g} / \mathrm{well}$. Table 1 A shows zone of inhibition of A. sativum and P. emblica (crude extract). It was observed that the aqueous extracts of A. sativum showed remarkable activity against all the tested organisms with the highest activity found on Psudomonas sp. $(38 \mathrm{~mm}$ zone diameter) at $100 \mu \mathrm{g} / \mathrm{well}$ concentration. Zone of inhibition showed against A. sativum were satisfactory antimicrobial activity. Onyeagba 
et al. (2006) worked on the same (A. sativum) and found no zone of inhibition against A. sativum. This is may be due to the species difference or the A. sativum difference in different biologic condition. Aqueous extract of $P$. emblica was also showed a good activity against all the tested organisms. De Britto et al. (2011) showed satisfactory activity of $P$. emblica against Xanthomonas sp., Aeromonas sp. and Campestris hydrophila sp., but in present study it was more effective result was found aginst all the selected microbes. On the other hand, the ethanol extract of A. sativum (Table 2)is also active against the test organisms with highest activity on S. aureus $(17 \mathrm{~mm})$ at $100 \mu \mathrm{g} / \mathrm{disc}$, but Yusha'u et al (2008) observed that ethanol extract of A. sativum showed highest $(51 \mathrm{~mm})$ activity on E. coli at $200 \mu \mathrm{g} / \mathrm{disc}$ (Habib et al. (2007) reported sensitivity pattern of different microbes against chloroform extraction of $P$. emblica where no sensitivity was found whereas inpresent study, zone of inhibition was observed against all the tested organimsms. This difference of observation between Habib et al and present study may be due to species differences or ethanolic effect.

Determination of MIC and MBC It was observed that the MIC of A. sativum against Salmonella sp., S. typhi, B. cereus and $S$. aureus were $12.6 \mu \mathrm{g} / \mathrm{ml}$ whereas MIC against Klebsiella sp., was 3.12 S. paratyphi, MIC

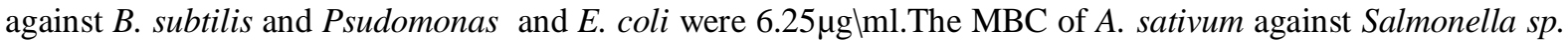
and $S$. paratyphi were $100 \mu \mathrm{g} \backslash \mathrm{ml}, 25 \mu \mathrm{g} \backslash \mathrm{ml}$ MBC was observed against Klebsiella sp. and E.coli and $50 \mu \mathrm{g} \backslash \mathrm{ml}$ MBC was observed against all other organisms (Fig 1A).Whereas, the MIC of A. sativum (ethanolic extract) against Klebsiella sp. Salmonella sp. and S. aureus were $50.0 \mu \mathrm{g} / \mathrm{ml}$ and Psudomonas sp. S. typhi, B. cereus, B. subtilis were $25.0 \mu \mathrm{g} \backslash \mathrm{ml}$. MBC were found $100 \mu \mathrm{g} \backslash \mathrm{ml}$ against all microbes (Fig 1B). In Figure 2A, it was observed that the MIC of P. emblica against Salmonella sp., S. typhi, B. cereus were $12.6 \mu \mathrm{g} / \mathrm{ml}$ whereas MIC against Klebsiella sp., S. paratyphi,MIC against B. subtilis and Psudomonas, S. aureus and E. coli were $6.25 \mu \mathrm{g} \backslash \mathrm{ml}$.The MBC of $P$. emblica against Salmonella sp. and $S$. paratyphi were $100 \mu \mathrm{g} \backslash \mathrm{ml}, 25 \mu \mathrm{g} \backslash \mathrm{ml}$ MBC was observed against $E$. coli and $50 \mu \mathrm{g} \backslash \mathrm{ml} \mathrm{MBC}$ was observed against all other organisms. It was observed that the MIC of P. emblica (ethanolic extract)against Salmonella sp., B. cereus B. subtilis and S. aureus were

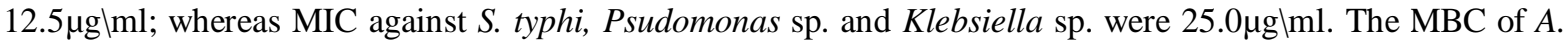
sativum against Salmonella sp., Klebsiella sp. Psudomonas sp. and S. paratyphi were $100 \mu \mathrm{g} / \mathrm{ml}$ and $50 \mu \mathrm{g} \backslash \mathrm{ml}$ MBC was observed against all other organisms (Fig 2B). Fani et al. (2007) studied on MIC of A. sativum against $S$. mutans ranged from $4-32 \mathrm{mg} / \mathrm{mL}$ which was slightly lower compared with our study where A. sativum (aqueous extract) showed MIC from 6.25 to $25 \mu \mathrm{g} / \mathrm{ml}$. This may be due to the species differences. Owhe-Ureghe et al. (2010) observed that the MIC of A. sativum against the test isolates ranged from $31.25-62.5 \mathrm{mg} / \mathrm{mL}$ whereas in present study, MIC of A. sativum ranges from 6.25-25.0 $\mu \mathrm{g} \mathrm{lml}$ in case of aqueous exrtracts.

Comparison with commercial antibiotics In case of Klbesiella sp., highest zone of inhibition was observed $38 \mathrm{~mm}$ against A. sativum (aqueous). Clear zone of inhibition of $19 \mathrm{~mm}$ was found in case of P. emblica (aqueous); whereas 29, 25 and $17 \mathrm{~mm}$ clear zone were observed against Tetracycline, Ciproflaxacin and Cholamphenicol, respectively. In case of Psudomonas sp. 39 and $21 \mathrm{~mm}$ clear zones were showed against $A$. sativum (aqueous) and $P$. emblica (aqueous) respectively whereas clear zone by choramphenicol and ciprofloxacin were $23 \mathrm{~mm}$. At the time of $S$. typhi clear zones were 30 and $22 \mathrm{~mm}$ against $A$. sativum (aqueous) and $P$. emblica (aqueous), respectively. 28 and $20 \mathrm{~mm}$ clear zones were showed against Cholamphenicol and Ciproflaxacin (Figure 3A). In case of E.coli clear zone of inhibition of 20 and $29 \mathrm{~mm}$ was observed against $P$. emblica (aqueous) and A. sativum (aqueous), respectively; whereas zone of inhibition by Ciproflaxacin, Cefotaxime, Choramphenicol and Gentamicin were 30, 29, 26 and 28, respectively against E.coli. In case of $B$. subtilis, zone of inhibition $32 \mathrm{~mm}$ was found against $A$. sativum, at the same time, zone of inhibition of $30 \mathrm{~mm}$ was observed against Ciproflaxacin. In case of B. cereus A. sativum (aqueous) and $P$. emblica (aqueous) showed 34 and 20mm zone of inhibition. Clear zone by Ciproflaxacin, Merupenam and Vancomycin were 30, 30 and $20 \mathrm{~mm}$, respectively (Figure 3B). Satisfactory results were observed only in case A. sativum and P. emblica (aqueous extract) as compared with commercial antibiotics. Sometimes A. sativum was better than the commercial one.

Extracts of P. emblica, A. sativum and showed that they are effective against all the tested pathogens Psudomonas sp., S. aereus, Salmonella sp., S. typhi, S. paratyphi, B. cereus, B. subtilis, E. coli, S. aureus in controlling their growth in vitro in culture condition. They all have a bacteristatic and bactericidal activity when tested in vitro using crude preparation. All of the plant products (Aqueous and ethanolic) A. sativum and $P$. emblica (aqueous extract)were best they both could be able to inhibit the growth of all the sensitive microbes. Here the microbes we selected for our experiment can cause different types of diseases.As aqueous extracts of A. sativum and $P$. emblica are more sensitive to the microbes.Although in some cases A. sativum was more effective than commercial antibiotics like tetracycline and chloramphenicol. gallic and P. emblica may be used successfully for treating various diseases causing microbes agent S. aureus., Salmonella, E. coli, S. aureus etc. Further in vivo studies are necessary. 


\section{Reference}

[1] Aibinu, I., Adenipekun, T., Adelowotan, T., Ogunsanya, T. and Odugbemi, T. (2007) Evaluation of the antimicrobial properties of different parts of Citrus aurantifolia (lime fruit) as used locally. Afr. J. Trad. Complem. Alter. Med. 4(2): 185-195.

[2] De Britto, A. J., Gracelin, D. H. S. and Sebastian, S. R. (2011) Antibacterial activity of a few medicinal plants against Xanthomonas campestris and Aeromonas hydrophila". J. Biopest. 4 (1): 57 - 60 (2011).

[3] Gardner, C., Chatterjee, L. M., Carlson, J. J. (2003) Soy garlic and ginkgo biloba: their potential role in cardiovascular disease prevention and treatment. Curr. Atheroscler Rep. 5: 468-475.

[4] Kris-Etherton, P. M. (2002) Bioactive compounds in foods: Their role in the prevention of cardiovascular disease and cancer. J. Am. Med. 113: 71-88.

[5] Yeh YY, Liu L (2001). Cholesterol lowering effect of garlic extracts and organosulfur compounds: Human and Animal studies. J. Nutr. 131: 989-993.

[6] Teferi, G. and Hahn, H. J. (2002) Treatment of malaria in Ethiopia folk medicine. Trop. Doc. 32: $206-207$.

[7] Murray PR, Baron EJ, Jorgensen JH, Landry ML, Pfaller MA (2007). $9^{\text {th }}$ edition. ASM Press, Washington DC. Man. Clin. Microbiol. p. 2260.

[8] Fani MM, Kohanteb J, Dayaghi M (2007). Inhibitory activity of garlic Allium sativum extract on multi drug resistant S.mutans. J. Indian Soc. Pedad. Prev. Dent. 25(4): 164-168.

[9] Owhe-Ureghe, U. B., Ehwarieme, D. A. and Eboh, D. O. (2010) Antibacterial activity of garlic and lime on isolates of extracted carious teeth. African J. Biotech. 9(21):3163-3166.

[10] Onyeagba, R. A., Ugbogu, O. C., Okeke, C. U., Iroakasi, O. (2006) Studies on the antimicrobial effects of garlic (Allium sativum Linn), ginger (Zingiber officinale Roscoe) and lime (Citrus aurantifolia Linn). Afr. J. Biotechnol. 3: 552-554.

Table 1 A: Determination of antimicrobial activity of $A$. sativum and $P$. emblica (Crude Extract)

\begin{tabular}{|c|c|c|}
\hline \multirow{2}{*}{ Name of organisms } & \multicolumn{2}{|c|}{ Zone of inhibition $\mathbf{( m m}$ ) } \\
\cline { 2 - 3 } & A. sativum & P. emblica \\
\hline Psudomonas sp. & 38 & 20 \\
\hline S. typhi & 28 & 22 \\
\hline S. aureus & 24 & 24 \\
\hline E. coli & 27 & 18 \\
\hline Klebsiella sp. & 36 & 19 \\
\hline S. paratyphi & 30 & 21 \\
\hline B. subtilis & 28 & 20 \\
\hline Salmonella sp. & 39 & 19 \\
\hline B. cereus & 22 & 22 \\
\hline
\end{tabular}

Table 1B: Determination of antimicrobial activity of $A$. sativum and $P$. emblica (Ethanolic Extract)

\begin{tabular}{|c|c|c|}
\hline \multirow{2}{*}{ Name of organism } & \multicolumn{2}{|c|}{ Zone of inhibition (mm) } \\
\cline { 2 - 3 } & A. sativum & P. emblica \\
\hline Klebsiella sp. & 11 & 15 \\
\hline B. subtilis & 12 & 16 \\
\hline B. cereus & 6 & 11 \\
\hline Psudomonas sp. & 17 & 15 \\
\hline S.typhi & 10 & 9 \\
\hline E. coli & 0 & 0 \\
\hline S. paratyphi & 0 & 9 \\
\hline S. aureus & 17 & 10 \\
\hline
\end{tabular}

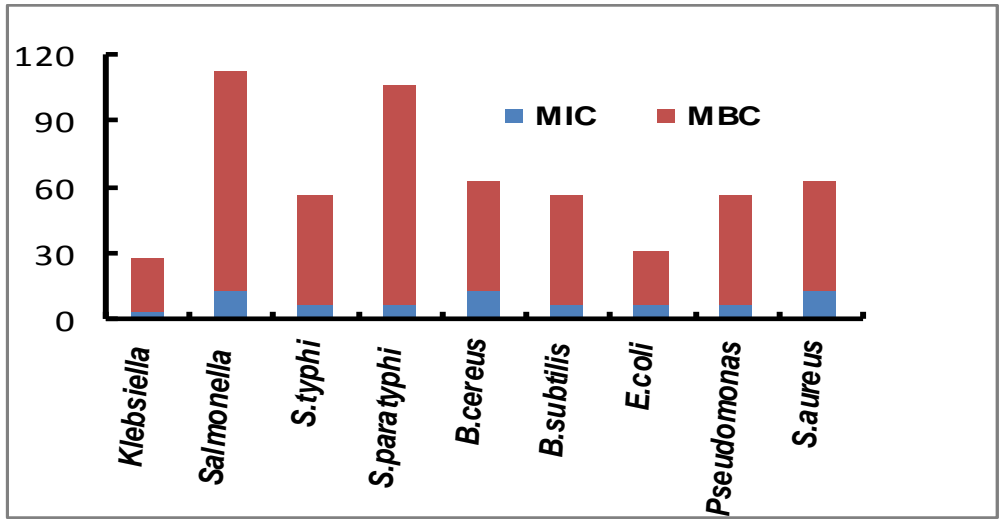

Figure1A- Determination of MIC and MBC of $A$. sativum (crude extract) 


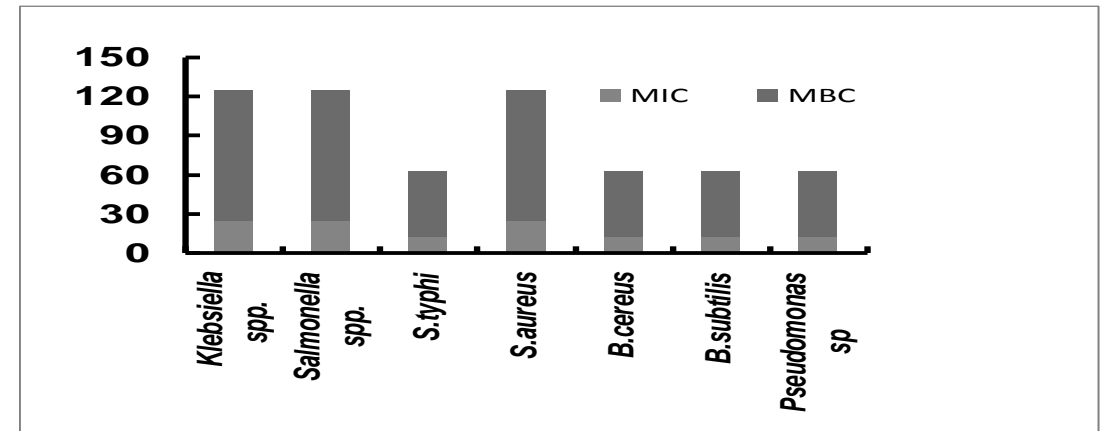

Figure1B- Determination of MIC and MBC of A. sativum (Ethanolic extract)

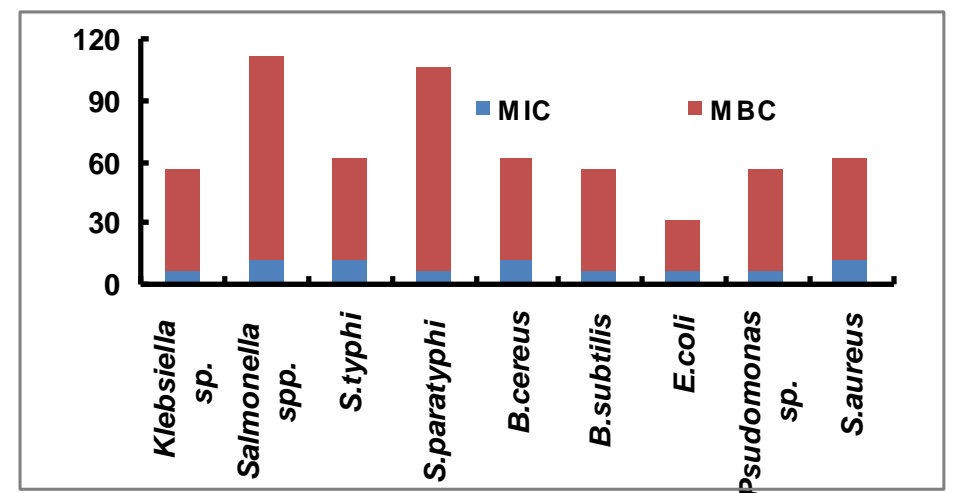

Figure 2A - Determination of MIC and MBC of $P$. emblica (crude extract)

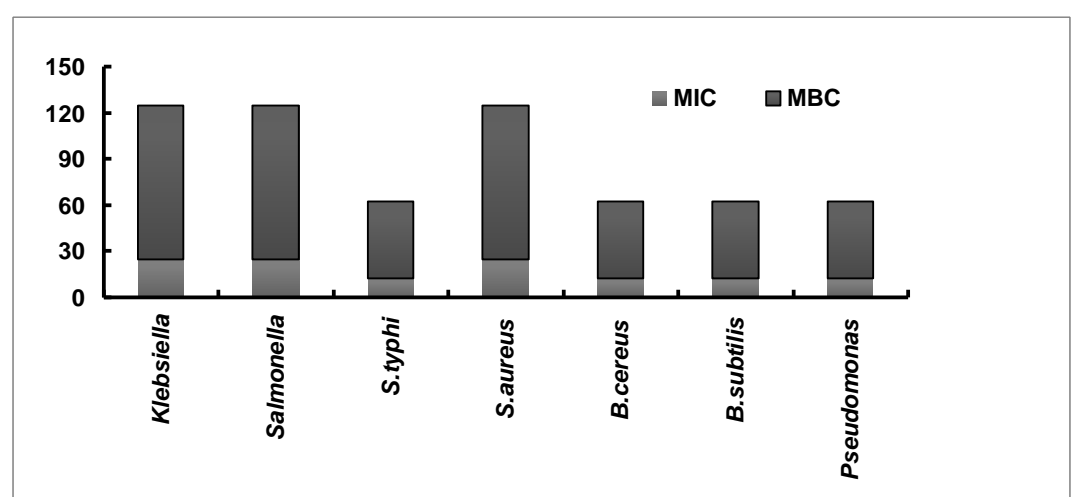

Figure 2B - Determination of MIC and MBC of P. emblica (Ethanolic extract)

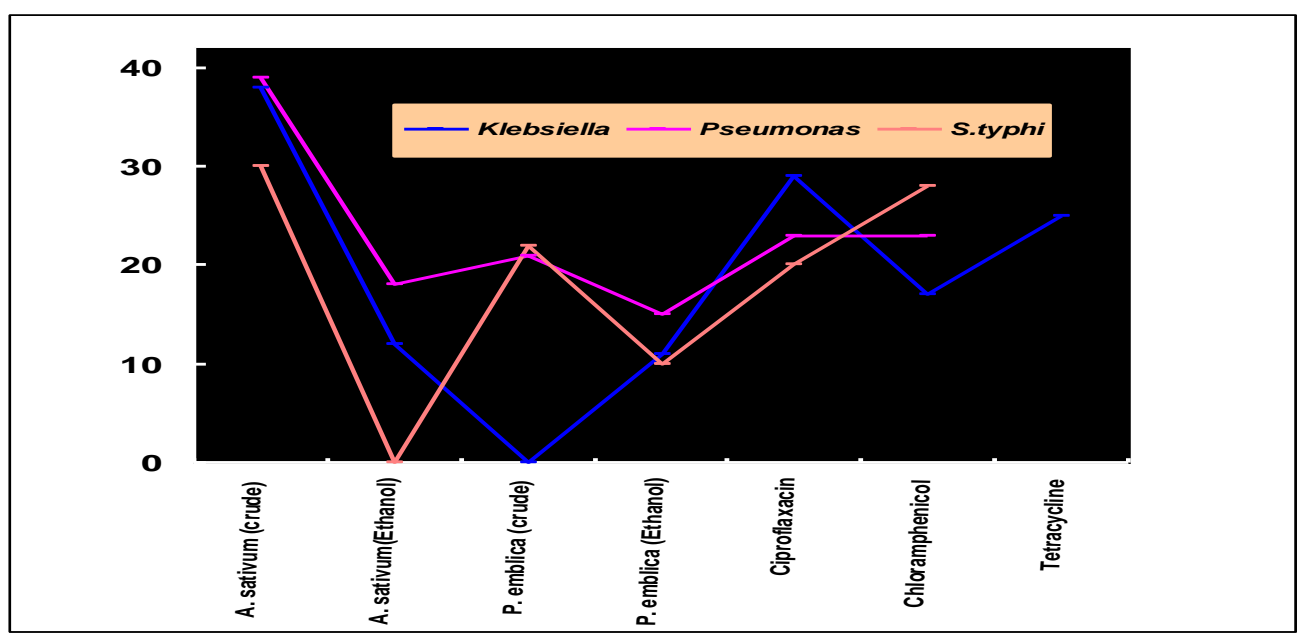

Fig. 3 A: Comparative analysis of A. sativum and P. emblica with commercial antibiotics 


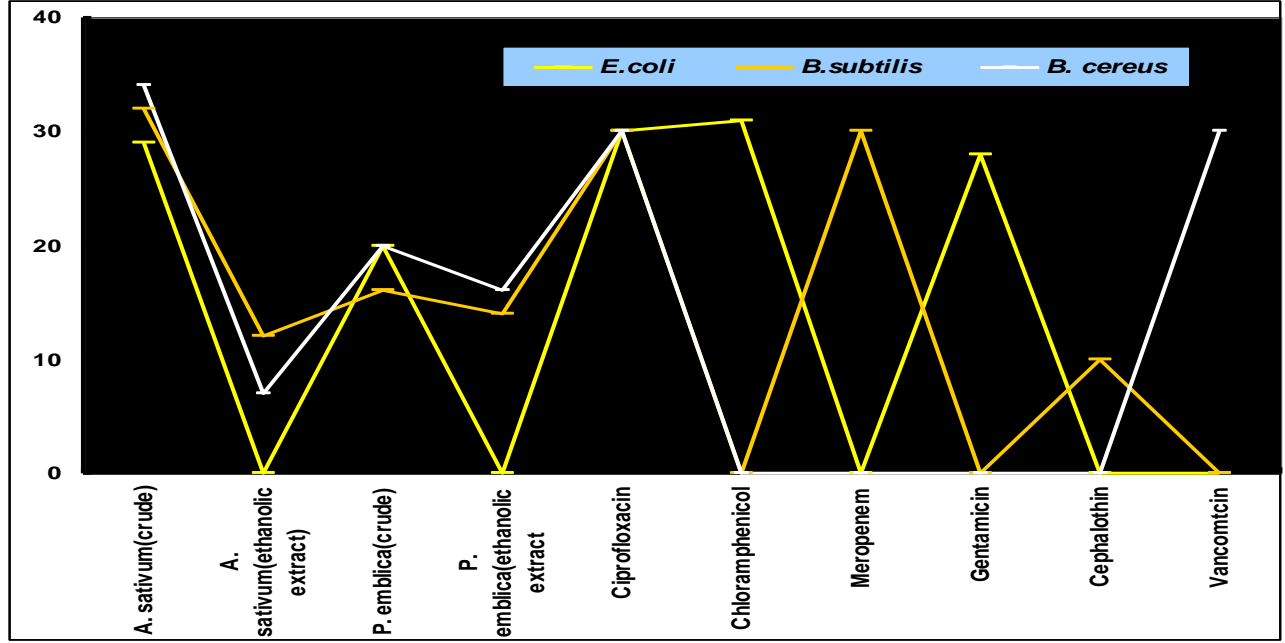

Fig. 3 B: Comparative analysis of $A$. sativum and P. emblica with commercial antibiotics 